\title{
Food habit of Platydemus manokwari De Beauchamp, 1962 (Tricladida: Terricola: Rhynchodemidae), known as a predatory flatworm of land snails in the Ogasawara (Bonin) Islands, Japan
}

\author{
Takashi OHBAYASHI, ${ }^{1, *, \dagger}$ Isamu OKOCHI, ${ }^{2}$ Hiroki SATO ${ }^{2}$ and Tsuyoshi ONo ${ }^{1}$ \\ ${ }^{1}$ Agricultural Pest Division, Ogasawara Subtropical Branch of Tokyo Metropolitan Agricultural Experiment Station; Tokyo 100- \\ 2101, Japan \\ ${ }^{2}$ Department of Forest Entomology, Forestry and Forest Products Research Institute; Ibaraki 305-8687, Japan
}

(Received 26 August 2004; Accepted 5 July 2005)

\begin{abstract}
The distribution and food habit of the flatworm species Platydemus manokwari, which is known to be a predator of land snails, were examined on Chichijima Island of the Ogasawara (Bonin) Islands, Japan. P. manokwari was distributed over a wide area of the island. Few live land snails were found in the area where P. manokwari was distributed. Further, it was revealed that $P$. manokwari fed not only on live land snails including predatory species, but also on other food resources such as live flatworms or a land nemertean species and the carcasses of slugs and earthworms. Therefore, P. manokwari is expected to survive even if the populations of land snails are almost lost on Chichijima Island in the future, and so will affect the biodiversity of Chichijima Island.
\end{abstract}

Key words: Platydemus manokwari; Euglandina rosea; Achatina fulica; decline of land snails; Ogasawara (Bonin) Islands

\section{INTRODUCTION}

The Ogasawara (Bonin) Islands are located in the northern Pacific Ocean about 1,000 km south of the mainland of Japan. More than 100 species of land mollusks have been recorded on the islands, of which $94 \%$ are endemic to the islands (Tomiyama and Kurozumi, 1992; Tomiyama, 1994).

However, about $70 \%$ of the endemic species have already become extinct (Tomiyama, 2002). The decline and extinction of endemic land snails in tropical oceanic islands is a major concern for conservation biology (Clarke et al., 1984; Hopper and Smith, 1992; IUCN/SSC Mollusc Specialist Group, 1995). Furthermore, the population of introduced species such as the giant African snail Achatina fulica has also declined in recent years on Chichijima Island (Tomiyama, 1991; Ohbayashi, 2002).

The following possible reasons for this decline on Chichijima Island have been pointed out: introduction of the predatory snail Euglandina rosea for the control of $A$. fulica in 1965 (Takeuchi et al., 1991); predation by a predatory flatworm (Okochi et al., 2004); invasion of the alien predatory flatworm Platydemus manokwari since the 1990s (Kawakatsu et al., 1999; Tomiyama, 2002); predation by alien rats (Tomiyama, 2002); and forest destruction (Tomiyama, 2002).

Among them, two invasive aliens, E. rosea and P. manokwari, could be major reasons because they invaded only Chichijima Island, which would explain the sharp decline of both endemic and exotic snails on Chichijima Island. The most likely cause of the decline of land snails on Chichijima Island is thought to be the invasion of $P$. manokwari in the 1990s (Tomiyama, 2002).

Although land snails have already become extinct in most areas on Chichijima Island (Tomiyama and Kurozumi, 1992; Tomiyama, 1994), P. manokwari remains distributed over these areas (Ohbayashi, 2002). Furthermore, there used to be other land planarians (including snail predators) and land nemertean worms distributed on Chichijima Island (Kawakatsu et al., 1999), but in

\footnotetext{
* To whom correspondence should be addressed at: E-mail: Takashi_Oobayashi@member.metro.tokyo.jp

$\dagger$ Present address: Tokyo Metropolitan Plant Protection Office, 3-8-1 Fujimi-cho, Tachikawa, Tokyo 190-0013, Japan DOI: 10.1303/aez.2005.609
} 
recent years there are few in areas where $P$. manokwari has already invaded, suggesting that these land planarians and land nemerteans have been defeated by interspecific competition with $P$. manokwari (Ohbayashi, 2002).

The food habit of $P$. manokwari has not been investigated previously in sufficient detail. Waterhouse and Norris (1987) noted, as a personal communication from Winsor (1985), that P. manokwari feed on anything other than live land snails, while Kaneda et al. (1990) reported that P. manokwari preyed only on live land snails. Furthermore, Hopper and Smith (1992) suggested that P. manokwari also feeds on another alien predatory snail, $E$. rosea, but this has not been verified. It is important to clarify the food habit of $P$. manokwari and interspecific relationships among $P$. manokwari and other predators for the conservation of endemic land snails.

This study was undertaken to clarify the food habit of $P$. manokwari, and to confirm the interactions between other predators of land snails.

\section{MATERIALS AND METHODS}

Distribution and field observation of the food habit of P. manokwari. All studies were conducted on Chichijima Island, the largest island in the Ogasawara (Bonin) Islands.

We searched under stones and logs in the daytime of the years 1995, 1998, 2002, 2003, and 2004 (29 times in total, covering spring to winter, and search areas and months differed with years). The sites where both land snails and flatworms were recorded (whether at the same time or not) were regarded as areas of coexistence at the time of the search. We also conducted nighttime observations of the forest floor (once in the month in December 1998 and once every month from January to July, 2004), and recorded the sites where P. manokwari and live land snails were detected. During the survey of the distribution of $P$. manokwari, we recorded the species predated by the animal.

We also used $20 \mathrm{~cm} \times 20 \mathrm{~cm}$ mesh bags made of $5 \mathrm{~mm}$ nylon mesh as attractant traps in which one live A. fulca (shell height: over $40 \mathrm{~mm}$ ) was put. The traps were set on the forest floor near a road (45 sites) from March to May 1998, checked every few weeks, and the sites where P. manokwari was detected were recorded.
Feeding tests. Five species of live flatworms (Bipalium kewense (adults), Bipalium sp. (adults), Platydemus sp. -1 (adults), Platydemus sp. -2 (adults), and Australopacifica sp. (adults)), one species of live land nemertean (Geonemertes pelaensis (adults)), six species of live land snails and slugs (Achatina fulica (juveniles and adults), Limax marginatus (adults), Deroceras laebe (adults), Euglandina rosea (juveniles and adults), Bradybaena similaris (adults), and Acusta despecta sieboldiana (juveniles and adults)), and earthworms (Haplotaxida spp. (adults), dead or alive) were tested as the prey of P. manokwari (Table 1). Species of flatworms and land nemerteans were identified according to Kawakatsu et al. (1999).

One specimen of $P$. manokwari (body length: over $30 \mathrm{~mm}$ ) and one specimen of a test animal species were put together in a plastic cup $(\phi 90 \mathrm{~mm}$, $40 \mathrm{~mm}$ height) in which a paper towel moistened with distilled water was laid. They were kept at $25^{\circ} \mathrm{C}$ under room light conditions, and predation was checked every day for $10 \mathrm{~d}$.

Predation was detected by direct observation during the daytime (every hour from 07:00-23:00), and by video camera (SONY CCD-TRV86PK) recording during the night (23:00-07:00).

Cannibalism of $P$. manokwari was also tested. One, three or five specimens of mature $P$. manokwari (collected at different sites of Chichijima Island, body length: over $30 \mathrm{~mm}$ ) were put in a plastic cup ( $\phi 80 \mathrm{~mm}, 25 \mathrm{~mm}$ height) in which a paper towel moistened with distilled water was laid, and were checked every day for $10 \mathrm{~d}\left(25^{\circ} \mathrm{C}\right.$, room light conditions).

\section{RESULTS}

\section{Distribution and field observation of the food habit of $P$. manokwari}

P. manokwari is distributed over a wide area of Chichijima Island, except for the east and south coast areas (Fig. 1). In contrast, endemic snails are distributed only in the east and south coast areas (Fig. 1).

In nine sites of the 37 sites where $P$. manokwari was recorded, land snails and $P$. manokwari coexisted, but at the other 28 sites, only P. manokwari was recorded. Therefore, it was difficult to find live land snails in the area where P. manokwari was detected (Fig. 1), and only one trap (set at Kita- 


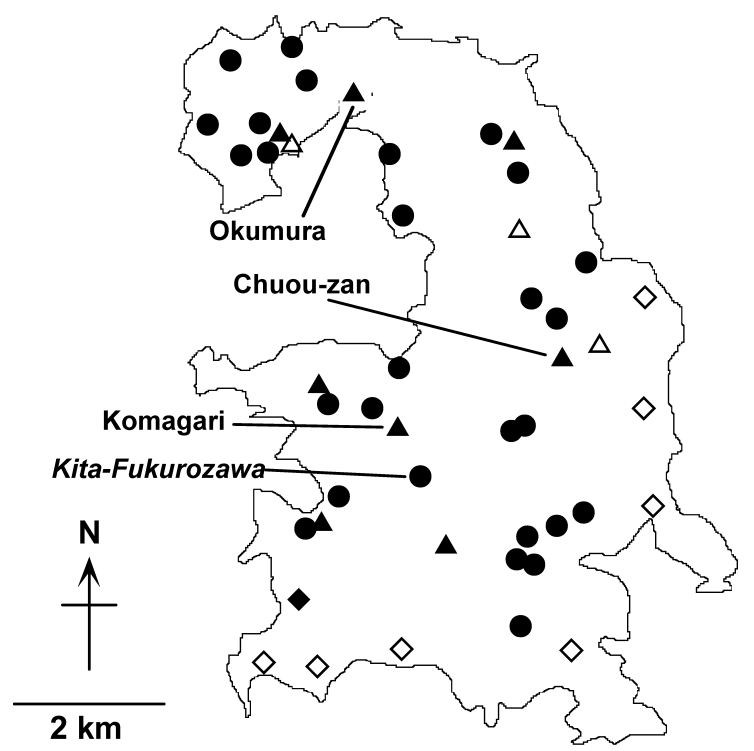

Fig. 1. Distributions of Platydemus manokwari and land snails (endemic/exotic) in Chichijima Island (1995-2004). Solid $(\boldsymbol{\nabla} / \mathbf{\Delta})$ and open $(\diamond / \triangle)$ symbols show whether $P$. manokwari was recorded or not, respectively. Patterns of symbols are as follows: 0 : no snails (both endemic and exotic) were recorded; $\diamond / \diamond$ : endemic snails were recorded; $\boldsymbol{\Delta} / \triangle$ : exotic snails were recorded. Points indicated by lines are where predation of $P$. manokwari was recorded. The point "KitaFukurozawa" is the point where one of the attractant traps was set).

Fukurozawa) of the 45 traps attracted $P$. manokwari (Fig. 2b).

In the field research, it was observed that $P$. manokwari preyed on live land nemertean ( $G$. pelaensis) at Chuou-zan (14 Nov. 2002: Figs. 1 and 2a), attacked live A. fulica put in the mesh bag at Kita-Fukurozawa (11 Mar. 1998: Figs. 1 and 2b), fed on the carcass of slug (Incilaria sp.) at Chuouzan (19 Aug. 2002: Figs. 1 and 2c), attacked live $E$. rosea at Okumura (23 Apr. 2002: Figs. 1 and 2d), and fed on the carcass of earthworms (Haplotaxida spp.) at Komagari (4 Dec. 1998: Figs. 1 and 2e).

In the case of E. rosea, three P. manokwari attacked one E. rosea at the same time ("gang-attack": Mead, 1963). The shell height of the E. rosea was $57.6 \mathrm{~mm}$, and the wet body weights of the $P$. manokwari were $0.37,0.27$ and $0.21 \mathrm{~g}$, respectively.

\section{Feeding tests}

P. manokwari preyed on live land planarians (except $P$. manokwari), live land nemerteans, and live land snails (including E. rosea) tested within $10 \mathrm{~d}$
(Table 1). Further, P. manokwari fed on the carcass of earthworms within $10 \mathrm{~d}$, but did not prey on live earthworms at all for more than $10 \mathrm{~d}$ (Table 1). Cannibalism was not observed at all for more than $10 \mathrm{~d}$.

When $P$. manokwari attacked snails, other planarians and a land nemertean, it followed their trails. When P. manokwari fed on land snails, it bent its mid-abdomen and inserted it into the aperture of the prey, then digested the flesh of the snail and sucked (Fig. 3a). Meanwhile, when P. manokwari fed on land planarians and land nemerteans, it extruded a proportionately long, white proboscis near the mid-ventral surface of the body, and sucked directly (Fig. 3b).

\section{DISCUSSION}

We confirmed that $P$. manokwari feeds not only on live land snails, but also on other species of live flatworms or land nemerteans, and on the carcasses of slugs and earthworms, both in the field and in captivity.

There used to be other land planarians (such as Bipalium sp.) and a land nemertean (G. pelaensis) distributed widely on Chichijima Island, but in recent years there are few in areas where P. manokwari has already invaded (Kawakatsu et al., 1999; Ohbayashi, 2002). This is in contrast to the abundance of these land planarians and a land nemerteans on Hahajima Island, which has not been invaded by P. manokwari (Kawakatsu et al., 1999; Okochi et al., 2004). Therefore, these land planarians and land nemerteans may have been consumed by $P$. manokwari on Chichijima Island.

The food habit of $P$. manokwari suggests that the reason why $P$. manokwari still exist in areas where both the number of endemic and exotic land snails has already been reduced may be that $P$. manokwari can use food resources other than live land snails.

On the other hand, on Hahajima Island, other species of predatory flatworms (such as Bipalium sp., Platydemus sp. -1, and Australopacifica sp.) eradicated endemic snails but are coexisting with exotic snails because they need live snails as food (Okochi et al., 2004).

We also confirmed that $P$. manokwari feeds on $E$. rosea, a predatory land snail, both in the field and in captivity, suggesting that $P$. manokwari may be a major reason why E. rosea populations have de- 

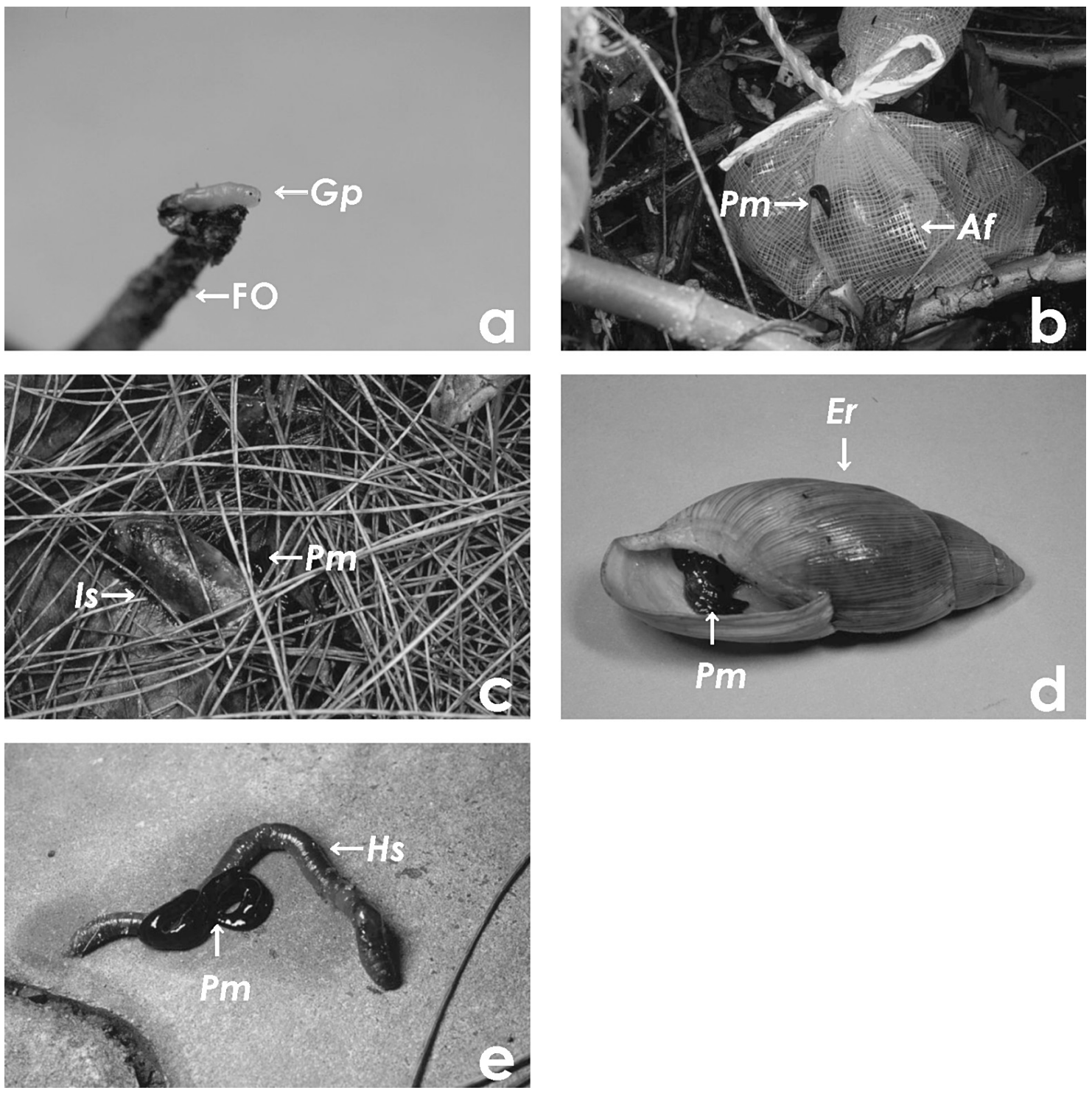

Fig. 2. Feeding on various food resources by Platydemus manokwari $(P m)$ on Chichijima Island. a: Head region of land nemertine (Geonemertes pelaensis: Gp, photograph in the laboratory, FO: forceps holding the head region); b: live Achatina fulica (Af) put in mesh bag; c: carcass of slug (Incilaria sp.: Is); d: live Euglandina rosea (Er, photograph in the laboratory); e: carcass of earthworm (Haplotaxida sp.: Hs).

creased on Chichijima Island, as well as those in other tropical oceanic islands such as Guam (Hopper and Smith, 1992).

Therefore, as P. manokwari can use various food resources, this flatworm is expected to survive in the future and make it difficult for the land snails of Chichijima Island to survive.

Furthermore, adults of $P$. manokwari were not observed to cannibalize each other. This suggests that there may be no chance of population limitation by cannibalism.

In conclusion, it has been confirmed that the in- troduced predatory flatworm $P$. manokwari presently poses a major threat to the survival of both the endemic and exotic land snails, including E. rosea on Chichijima Island at present. This animal may also cause a reduction of other land snail predators such as other flatworms. Therefore, $P$. manokwari threatens the biodiversity of Chichijima Island.

It is important to take measures to prevent the further invasion of $P$. manokwari to other islands for the conservation of endemic land snails, land planarians, and land nemertine. Such action is also 
Table 1. Predation on various food resources in captivity by Platydemus manokwari

\begin{tabular}{|c|c|c|c|c|}
\hline Food resources & Size $(\mathrm{mm})^{\mathrm{a}}$ & $N^{\mathrm{b}}$ & Number of prey & $\begin{array}{c}\text { Days to start of } \\
\text { preying }\end{array}$ \\
\hline \multicolumn{5}{|l|}{ Live land planarians } \\
\hline Bipalium kewense & $>60$ & 2 & $1^{\mathrm{c}}$ & 1 \\
\hline Bipalium sp. & $>25$ & 6 & $5^{\mathrm{d}}$ & $1-6$ \\
\hline Platydemus manokwari & $>30$ & 4 & 0 & - \\
\hline Platydemus sp. -1 & $>15$ & 1 & 1 & 1 \\
\hline Platydemus sp. -2 & $>35$ & 4 & 4 & $1-10$ \\
\hline Australopacifica sp. & $>15$ & 1 & 1 & 1 \\
\hline \multicolumn{5}{|l|}{ Live land nemertine } \\
\hline Geonemertes pelaensis & $>25$ & 3 & 3 & $2-6$ \\
\hline \multicolumn{5}{|l|}{ Live land snails and slugs } \\
\hline Achatina fulica & $<5,>50$ & 4 & $4^{\mathrm{e}}$ & $6-7$ \\
\hline Limax marginatus & $>25$ & 2 & 2 & 1 \\
\hline Deroceras laebe & $>15$ & 7 & 7 & $1-3$ \\
\hline Euglandina rosea & $<5,>50$ & 2 & $2^{\mathrm{e}}$ & $1-5$ \\
\hline Bradybaena similaris & $>10$ & 1 & 1 & 2 \\
\hline Acusta despecta sieboldiana & $<5,>20$ & 5 & $5^{\mathrm{e}}$ & $1-7$ \\
\hline \multicolumn{5}{|l|}{ Earthworm } \\
\hline Haplotaxida spp. (live) & $>50$ & 5 & 0 & - \\
\hline Haplotaxida spp. (dead) & $>50$ & 5 & 5 & 1 \\
\hline
\end{tabular}

\footnotetext{
${ }^{a}$ Body length (planarians, nemertine, slugs, and earthworm) or shell heights (snails).

${ }^{\mathrm{b}}$ Number of trials.

${ }^{\mathrm{c}}$ During experiment, one Bipalium kewense dead (not by predation).

${ }^{\mathrm{d}}$ During experiment, one Bipalium sp. dead (not by predation).

${ }^{\mathrm{e}}$ Both young and adult snails were preyed upon.
}
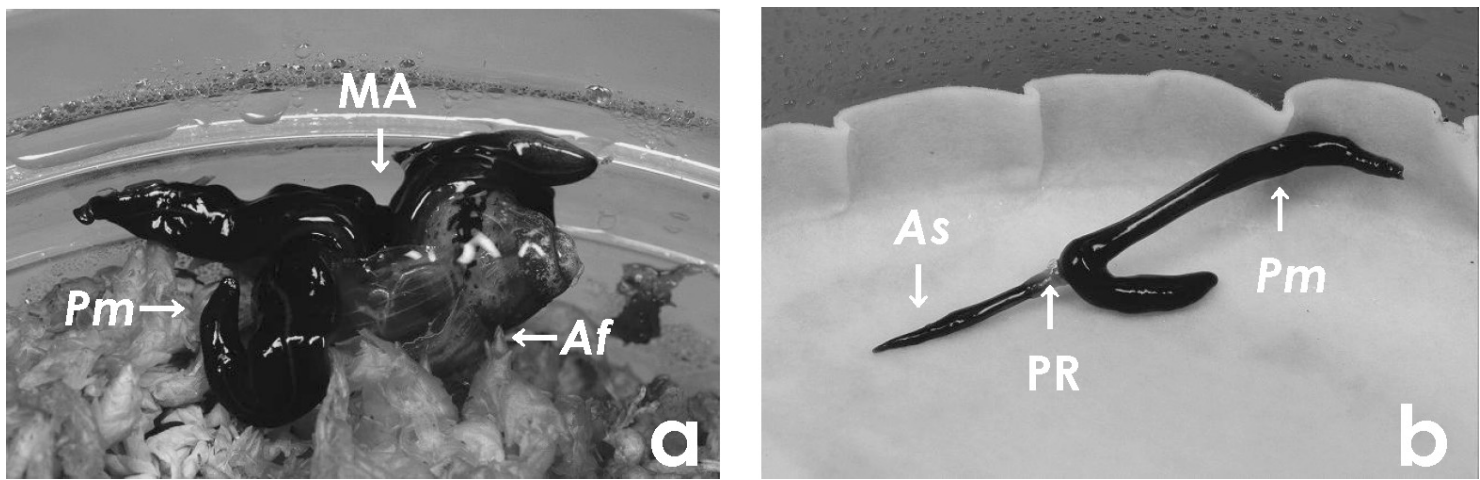

Fig. 3. Styles of predation by Platydemus manokwari (Pm). a: live snail, Achatina fulica (Af);. b: live land planarians, Australopacifica sp. (As). MA: mid-abdomen; PR: proboscis.

required on other tropical oceanic islands of the world.

\section{ACKNOWLEDGEMENTS}

We thank Dr. Satoshi Chiba of Tohoku University, Dr. Masaharu Kawakatsu, Dr. Kiyonori Tomiyama of Kagoshima University, Mr. Nathaniel Savory Jr. and Mr. Koji Takeuchi for their helpful advice. We also thank Ms. Toshie Suzuki-Sato, who first detected that $P$. manokwari fed on the carcasses of earthworms in the field. We also thank Ms. Fumiko Yumura, Ms. Yukari Niikawa, Ms. Noriko Saito-Karashima, and Ms. Nobuko Ono for their help in the field survey. Thanks are also due to Dr. Simon Lawson, Queensland Forestry Research Institute, for his correction of the English in this manuscript. 


\section{REFERENCES}

Clarke, B., J. Murray and M. S. Johnson (1984) The extinction of endemic species by a program of biological control. Pacific Science 38: 97-104.

Hopper, D. R. and B. D. Smith (1992) Status of tree snails (Gastropoda: Partulidae) on Guam, with a resurvey of sites studied by H. E. Crampton in 1920. Pacific Science 46: 77-85.

IUCN/SSC Mollusc Specialist Group (1995) Statement of concern and summary of recommendations. Tentacle 5: 13.

Kaneda, M., K. Kitagawa and F. Ichinohe (1990) Laboratory rearing method and biology of Platydemus manokwari De Beauchamp (Tricladida: Terricola: Rhynchodemidae). Appl. Entomol. Zool. 25: 524-528.

Kawakatsu, M., I. Okochi, H. Sato, T. Ohbayashi, K. Kitagawa and K. Totani (1999) A preliminary report on land planarians (Tubellaria, Seriata, Tricladida, Terricola) and land nemertine (Enopla, Hoplonemertea, Monostylifera) from the Ogasawara Islands. Occasional Publications, Biological Laboratory of Fuji Women's College, Sapporo (Hokkaido), Japan No. 32.

Mead, A. R. (1963) A flatworm predator of the giant African snail Achatina fulica in Hawaii. Malacologia 1: 305311.

Ohbayashi, T. (2002) Studies on the Ecology and Control of
Achatina fulica in the Ogasawara Islands. Tokyo Metropolitan Government, Tokyo. 66 pp. +3 pls. (in Japanese).

Okochi, I., H. Sato and T. Ohbayashi (2004) The cause of mollusk decline in the Ogasawara Islands. Biodiversity and Conservation 13: 1465-1475.

Takeuchi, K., S. Koyano and K. Numazawa (1991) Occurrence of the giant African snail in the Ogasawara (Bonin) Islands, Japan. Micronesia Suppl. 3: 109-116.

Tomiyama, K. (1991) Terrestrial molluscan fauna of Chichijima Islands, the Ogasawara Islands, with special reference to Ani-jima island. Ogasawara Research No. 17/18: 1-31 (in Japanese with English summary).

Tomiyama, K. (1994) Factors affecting the extinction of land snails on the Ogasawara Islands. Venus 53: 152-156 (in Japanese).

Tomiyama, K. (2002) Land mollusks of the Ogasawara Islands - the weakness of Oceanic island species. Shinrin Kagaku 34: 25-28 (in Japanese).

Tomiyama, K. and T. Kurozumi (1992) Terrestrial mollusks and conservation of their environment in the Ogasawara Islands. Regional Views 5: 39-81 (in Japanese with English summary).

Waterhouse, D. F. and K. R. Norris (1987) Achatina fulica Bowdich. In Biological Control-Pacific Prospects (D. F. Waterhouse and K. R. Norris eds.). Inkata Press, Melbourne. pp. 265-273. 